\title{
Solusi Model Aliran Gas Dalam Pipa pada Kondisi Line Packing Menggunakan Skema Richtmyer
}

\author{
Harry Budiharjo Sulistyarso ${ }^{1,3,4}$, Suryasatriya Trihandaru ${ }^{2,4}$, Leksono \\ Mucharam $^{1,4}$, Septoratno Siregar ${ }^{1,4}$, Ivanky Saputra ${ }^{4} \&$ Sinatra Canggih $^{4}$ \\ ${ }^{1}$ Departemen Teknik Perminyakan Institut Teknologi Bandung \\ ${ }^{2}$ Departemen Matematika Institut Teknologi Bandung \\ ${ }^{3}$ Jurusan T. Perminyakan UPN "Veteran" Yogyakarta \\ ${ }^{4}$ KPP Matematika Industri dan Terapan Institut Teknologi Bandung
}

\begin{abstract}
Abstrak. Line packing adalah suatu proses penyimpanan gas dalam pipa dengan cara memperbesar laju alir di inlet sementara laju alir outlet dipertahankan konstan. Perbedaan laju alir ini menyebabkan sifat alirannya menjadi unsteadystate (transient). Proses line packing dilakukan untuk menjamin pasokan gas selama terjadi masalah. Pada makalah ini, model aliran transient beserta permasalahan pada batas akan diselesaikan secara numerik menggunakan skema Richtmyer, hal ini disebabkan karena analisis kestabilan menunjukkan bahwa skema Richtmyer lebih baik dari skema eksplisit lainnya. Dari contoh kasus yang diberikan, diperoleh hasil bahwa skema Richtmyer cukup mendekati data di lapangan, yang kebanyakan merupakan kasus aliran unsteady-state.
\end{abstract}

Kata Kunci: line packing; skema Richtmyer; transient; unsteady-state.

\begin{abstract}
Line packing is a process storing gas in pipeline by increasing inlet gas flow rate while outlet gas flow rate is kept constant. This difference of gas flow rate causes the gas flow in pipeline being transient. Line packing process is intended to guarantee gas supply when trouble occurs. In this paper, a transient model with boundary condition is solved numerically using Richtmyer scheme, because stability analysis showed that Richtmyer scheme is better than other explicit schemes. In the case presented, it is shown that Richtmyer scheme sufficiently agrees with the real data in gas pipeline transmission, which is in many cases unsteady-state.
\end{abstract}

Keywords: line packing; Richtmyer scheme; transient; unsteady-state.

\section{$1 \quad$ Pendahuluan}

Selama ini pemodelan suatu aliran gas alam dalam pipa dilakukan dengan mengasumsikan bahwa aliran adalah steady (tunak) [6,11]. Pada beberapa kondisi asumsi ini memberikan hasil yang cukup baik. Namun demikian pada kenyataannya terdapat banyak situasi dimana asumsi ini memberikan hasil yang tidak dapat diterima di lapangan misalnya dalam kondisi line packing. Oleh 
karena itu harus dibangun suatu model matematika yang merepresentasikan aliran gas dalam pipa yang tidak tunak (transien).

Line Packing adalah penyimpanan gas sementara pada jaringan pipa. Hal ini dilakukan dengan membuat laju alir di inlet lebih besar daripada di outlet dan akibatnya sejumlah gas tersimpan dalam pipa setiap waktunya. Proses line packing hanya bisa dilakukan selama jangka waktu tertentu karena bertambahnya tekanan akan mencapai tekanan maksimum yang merupakan batas kekuatan pipa. Oleh karena itu, distribusi aliran yang mencakup distribusi tekanan dan laju alir penting selama proses line packing.

Junyang Zhou dan Adewumi [9] telah melakukan penelitian untuk mensimulasikan aliran gas dalam pipa, dengan menggunakan skema numerik Total Variations Diminishing (TVD) yang memiliki tingkat kesulitan yang tinggi dan bila dilihat dari segi numerik mempunyai waktu komputasi yang lama. Kemudian mereka mencoba lagi meneliti hal yang sama dengan menggunakan skema numerik Godunov, yang sedikit lebih sederhana [10]. Kedua skema numerik yang mereka gunakan memberikan hasil yang cukup mendekati data lapangan.

Pada makalah ini akan dicoba penggunaan skema Richtmyer yang lebih sederhana dan mudah dipahami. Skema ini cukup baik dalam merepresentasikan distribusi aliran dalam pipa. Di samping itu dari segi numerik, skema ini mempunyai tingkat kestabilan yang lebih baik dibandingkan skema-skema numerik lainnya terhadap penyelesaian persamaan aliran gas transien dalam pipa khususnya dalam kondisi line packing. Hal ini dibuktikan dengan hasil dari simulasi yang dapat dilihat pada sub bab 6 makalah ini.

\section{Model Matematika}

Aliran gas dalam pipa dapat dipandang sebagai masalah transportasi, dengan kuantitas yang ditransportasikan adalah massa dan momentum. Oleh karena itu model persamaan aliran gas dalam pipa diturunkan dari hukum konservasi massa dan momentum.

Melalui hukum konservasi massa, dapat diturunkan persamaan kontinuitas untuk rapat massa dalam bentuk persamaan diferensial parsial (PDP) satu dimensi sebagai berikut,

$$
\frac{\partial \rho}{\partial t}+\frac{\partial m}{\partial x}=0 .
$$


Kemudian dari hukum konservasi momentum untuk aliran gas dalam pipa akan didapatkan PDP untuk kekontinuitasan momentum seperti yang ditunjukkan di bawah ini,

$$
\frac{\partial(\rho u)}{\partial t}+\frac{\partial\left(\rho u^{2}\right)}{\partial x}=-\frac{\partial p}{\partial x}-\frac{f_{g} \rho u|u|}{2 D} .
$$

Persamaan keadaan yang akan dipakai adalah sebagai berikut,

$$
p=\frac{z R T}{M_{g}} \rho .
$$

Kemudian dengan mengasumsikan bahwa aliran dalam pipa isotermal, kita dapat memakai persamaan berikut untuk menghitung kecepatan suara dalam gas.

$$
c=\left(\frac{z R T}{M_{g}}\right)^{0.5} .
$$

Faktor gesekan yang akan dipakai dalam perhitungan didapatkan dari perhitungan untuk kasus steady-state dengan menggunakan korelasi Chen. Kemudian faktor deviasi $z$ dihitung menggunakan metode Dranchuck, Purvis dan Robinson [2, 4].

Dengan menulis $m=\rho u$ dan mensubstitusikan persamaan (2.3) dan (2.4) ke persamaan (2.1) dan (2.2), kita dapat menuliskan kembali menjadi sebuah sistem PDP non-linier yang hiperbolik dan non-homogen,

$$
\frac{\partial U}{\partial t}+\frac{\partial F(U)}{\partial x}=r(U)
$$

dengan

$$
U=\left(\begin{array}{c}
\rho \\
m
\end{array}\right), \quad F(U)=\left(\begin{array}{c}
m \\
\frac{m^{2}}{\rho}+c^{2} \rho
\end{array}\right), r(U)=\left(\begin{array}{c}
0 \\
-\frac{f_{g} m|m|}{2 D \rho}
\end{array}\right) .
$$

Beberapa asumsi di bawah ini digunakan untuk menyederhanakan permasalahan.

1. Aliran pada pipa pada kondisi awal adalah steady state, artinya gas tersebut tidak mengalami perubahan sifatnya terhadap waktu.

2. Temperatur diasumsikan sama pada setiap titik di sepanjang pipa, dan tidak ada perubahan terhadap waktu (isothermal).

3. Faktor gesekan dihitung saat kondisi steady state dan dipergunakan secara konstan untuk step waktu selanjutnya. 
4. Pipa lurus dan horisontal.

5. Aliran gas satu fasa dan menggunakan hubungan aliran satu dimensi.

\section{$3 \quad$ Metode Numerik}

Untuk mencari solusi pada masalah di atas khususnya mencari solusi analitik PDP (2.5) sangatlah sulit. Hal ini dikarenakan PDP tersebut mempunyai karateristik non linier, hiperbolik dan non homogen. Alternatifnya adalah dengan menggunakan metode numerik. Pada makalah ini kita akan menggunakan skema Richtmyer yang cocok untuk PDP yang non-linier dan hiperbolik.

Skema ini diturunkan dari metode Lax-Wendroff $[1,3]$ yang digunakan untuk menyelesaikan PDP linier yang hiperbolik dan homogen $\left(u_{t}+A u_{x}=0\right)$.

Dari deret Taylor didapatkan,

$$
u(x, t+\Delta t)=u(x, t)+\Delta t u_{t}(x, t)+\frac{1}{2} \Delta t^{2} u_{t t}(x, t)+\cdots
$$

karena $u_{t}+A u_{x}=0$ maka

$$
\begin{aligned}
& u_{t}=-A u_{x}, \\
& u_{t t}=-\left(A u_{x}\right)_{t}=-A\left(u_{t}\right)_{x}=-A\left(-A u_{x}\right)_{x}=A^{2} u_{x x},
\end{aligned}
$$

akibatnya

$$
u(x, t+\Delta t)=u(x, t)-\Delta t A u_{x}(x, t)+\frac{1}{2} \Delta t^{2} A^{2} u_{x x}(x, t)+\cdots
$$

Lalu komponen $u_{x}$ dan $u_{x x}$ diaproksimasi dengan hampiran beda pusat, sehingga hampirannya menjadi:

$$
\begin{aligned}
& u(x, t)=U_{j}^{n}, \\
& u_{x}(x, t)=\frac{U_{j+1}^{n}-U_{j-1}^{n}}{2 \Delta x}, \\
& u_{x x}(x, t)=\frac{U_{j+1}^{n}-2 U_{j}^{n}+U_{j-1}^{n}}{\Delta x^{2}} .
\end{aligned}
$$

Metode Lax-Wendroff mengambil 3 suku pertama dari deret (3.2) menjadi :

$$
U_{j}^{n+1}=U_{j}^{n}-\frac{\Delta t}{2 \Delta x} A\left(U_{j+1}^{n}-U_{j-1}^{n}\right)+\frac{\Delta t^{2}}{2 \Delta x^{2}} A^{2}\left(U_{j+1}^{n}-2 U_{j}^{n}+U_{j-1}^{n}\right) .
$$


Skema tersebut akan diperluas agar dapat digunakan untuk PDP yang nonlinier, salah satunya adalah dengan cara mengandaikan $A$ adalah matriks Jacobian dari $\mathrm{f}(\mathrm{u})$ pada persamaan konservasi $u_{t}+f(u)_{x}=0$ [3], maka skema numerik Lax Wendroff untuk PDP non linier adalah

$$
\begin{aligned}
& U_{j}^{n+1}=U_{j}^{n}-\frac{\Delta t}{2 \Delta x}\left(f\left(U_{j+1}^{n}\right)-f\left(U_{j-1}^{n}\right)\right)+\cdots \\
& \frac{\Delta t^{2}}{2 \Delta x^{2}}\left(A_{j+\frac{1}{2}}\left(f\left(U_{j+1}^{n}\right)-f\left(U_{j}^{n}\right)\right)-A_{j-\frac{1}{2}}\left(f\left(U_{j}^{n}\right)-f\left(U_{j-1}^{n}\right)\right)\right),
\end{aligned}
$$

dengan $A_{j \pm \frac{1}{2}}$ adalah matriks Jacobian yang dievaluasi $\operatorname{di} \frac{1}{2}\left(U_{j}^{n}+U_{j \pm 1}^{n}\right)$. Pada skema (3.4) kesulitan dihadapi saat menghitung matriks Jacobian dan biasanya lebih nyaman untuk menghitung $\mathrm{f}(\mathrm{u})$ daripada matriks. Oleh karena itu, Richtmyer mengubah skema satu langkah (3.4) menjadi skema dua langkah dengan tujuan untuk mengatasi kesulitan tersebut (lihat $[3,5])$.

$$
\begin{aligned}
& U_{j+\frac{1}{2}}^{n+\frac{1}{2}}=\frac{1}{2}\left(U_{j+1}^{n}+U_{j}^{n}\right)-\frac{\Delta t}{2 \Delta x}\left(F\left(U_{j+1}^{n}\right)-F\left(U_{j}^{n}\right)\right), \\
& U_{j}^{n+1}=U_{j}^{n}-\frac{\Delta t}{\Delta x}\left(F\left(U_{j+\frac{1}{2}}^{n+\frac{1}{2}}\right)-F\left(U_{j-\frac{1}{2}}^{n+\frac{1}{2}}\right)\right) .
\end{aligned}
$$

Skema ini akan digunakan untuk mencari solusi PDP (2.5). Namun karena PDP (2.5) non-homogen, maka skema (3.5) akan ditambah dengan faktor nonhomogennya, $r$ sehingga

$$
\begin{aligned}
& U_{j+\frac{1}{2}}^{n+\frac{1}{2}}=\frac{1}{2}\left(U_{j+1}^{n}+U_{j}^{n}\right)-\frac{\Delta t}{2 \Delta x}\left(F\left(U_{j+1}^{n}\right)-F\left(U_{j}^{n}\right)\right)+r\left(U_{j}^{n}\right) \Delta t, \\
& U_{j}^{n+1}=U_{j}^{n}-\frac{\Delta t}{\Delta x}\left(F\left(U_{j+\frac{1}{2}}^{n+\frac{1}{2}}\right)-F\left(U_{j-\frac{1}{2}}^{n+\frac{1}{2}}\right)\right)+r\left(U_{j}^{n}\right) \Delta t .
\end{aligned}
$$

\section{$4 \quad$ Normalisasi}

Untuk menjaga konsistensi satuan, menghindari konversi satuan yang berlebih dan sekaligus mempermudah proses numerik dilakukan normalisasi (penskalaan) terhadap suatu besaran tertentu. Selain itu, besar kecilnya nilai suatu besaran bisa diukur dengan membandingkan nilai tersebut dengan nilai variabel lain yang menjadi penormalnya. 
Selanjutnya, besaran-besaran yang terlibat pada persamaan aliran (2.5) akan dinormalkan. Posisi $(x)$ akan dinormalkan terhadap diameter pipa $(D)$, waktu $(t)$ terhadap waktu total gas menempuh jarak sepanjang $D$ dengan kecepatan suara $(D / c)$. Sedangkan kecepatan gas $(u)$ akan dinormalkan terhadap kecepatan suara (c) dan densitas tiap titik sepanjang pipa $(\rho)$ terhadap densitas inlet $\left(\rho_{0}\right)$. Misalkan tanda " $\sim$ " menyatakan notasi besaran yang sudah dinormalkan (tak berdimensi), maka secara matematis dapat dituliskan sebagai berikut

$$
\tilde{x}=\frac{x}{D}, \tilde{t}=t \frac{c}{D}, \quad \tilde{u}=\frac{u}{c}, \quad \tilde{\rho}=\frac{\rho}{\rho_{0}} .
$$

Dari definisi $m=\rho u$, diperoleh

$$
\tilde{m}=\tilde{\rho} \tilde{u}=\frac{\rho u}{\rho_{0} c}=\frac{m}{m_{0}} .
$$

Dengan menggunakan (4.1) dan (4.2), persamaan aliran (2.5) akan menjadi

$$
U_{\widetilde{t}}+F(U)_{\widetilde{x}}=r(U),
$$

dengan

$$
U=\left(\begin{array}{c}
\widetilde{\rho} \\
\tilde{m}
\end{array}\right), \quad F(U)=\left(\begin{array}{c}
\widetilde{m} \\
\frac{\widetilde{m}^{2}}{\widetilde{\rho}}+\widetilde{\rho}
\end{array}\right), r(U)=\left(\begin{array}{c}
0 \\
-\frac{f_{g} \tilde{m}|\widetilde{m}|}{2 \widetilde{\rho}}
\end{array}\right) .
$$

Persamaan aliran (4.3) adalah persamaan aliran yang besaran-besarannya sudah dinormalkan, dengan penormalnya didefinisikan oleh (4.1) dan (4.2). Selanjutnya, persamaan aliran inilah yang akan digunakan dan untuk kemudahan notasi, tanda " $\sim$ " pada besaran ternormalkan tidak disertakan dalam penulisan, dimulai dari persamaan (5.1) dan seterusnya.

\section{$5 \quad$ Kestabilan}

Analisis kestabilan yang akan digunakan adalah analisis Von Neumann. Akan tetapi, analisis Von Neumann hanya dapat diterapkan untuk PDP yang linier saja. Oleh karena itu suku non-linier pada PDP akan diabaikan karena ordenya yang cukup tinggi [1].

Skema Richtmyer adalah sebagai berikut:

$$
U_{j+\frac{1}{2}}^{n+1}=\frac{1}{2}\left(U_{j+1}^{n}+U_{j}^{n}\right)-\frac{\Delta t}{2 \Delta x}\left(F\left(U_{j+1}^{n}\right)-F\left(U_{j}^{n}\right)\right)+r\left(U_{j}^{n}\right) \Delta t
$$




$$
U_{j}^{n+1}=U_{j}^{n}-\frac{\Delta t}{\Delta x}\left(F\left(U_{j+\frac{1}{2}}^{n+1}\right)-F\left(U_{j-\frac{1}{2}}^{n+1}\right)\right)+r\left(U_{j}^{n}\right) \Delta t,
$$

dengan $j=1,2, \ldots, J-1$, dan

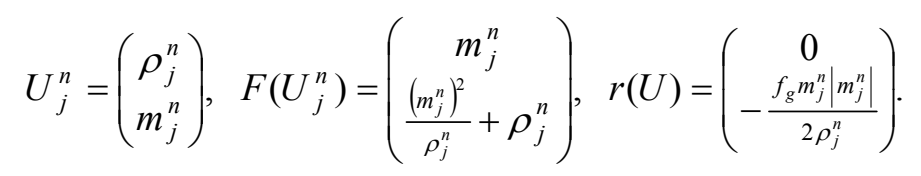

Namun di awal telah disebutkan bahwa suku non-linier pada skema dapat diabaikan, sehingga menjadi sebagai berikut:

$$
F\left(U_{j}^{n}\right)=\left(\begin{array}{c}
m_{j}^{n} \\
\rho_{j}^{n}
\end{array}\right), \quad r(U)=\left(\begin{array}{l}
0 \\
0
\end{array}\right) .
$$

Dengan menggunakan analisis Von Neumann, maka

$$
\begin{aligned}
& \rho_{j}^{n}=a_{1} e^{I j(k \Delta x)}, \\
& m_{j}^{n}=a_{2} e^{I j(k \Delta x)},
\end{aligned}
$$

dan dengan sifat eksponensial akan didapatkan

$$
\begin{aligned}
& \rho_{j \pm 1}^{n}=\rho_{j}^{n} e^{ \pm I(k \Delta x)}, \\
& m_{j \pm 1}^{n}=m_{j}^{n} e^{ \pm I(k \Delta x)} .
\end{aligned}
$$

Persamaan terakhir ini akan disubstitusikan ke skema (5.1) agar didapatkan matriks amplifikasi $G$, dengan $U^{n+1}=G U^{n}$. Dari perhitungan akan didapatkan $G$ sebagai berikut:

$$
\left(\begin{array}{cc}
1+\frac{\Delta t^{2}}{2 \Delta x^{2}}\left(e^{I(k \Delta x)}+e^{-I(k \Delta x)}\right)-\frac{\Delta t^{2}}{\Delta x^{2}} & -\frac{\Delta t^{2}}{2 \Delta x^{2}}\left(e^{I(k \Delta x)}-e^{-I(k \Delta x)}\right) \\
-\frac{\Delta t^{2}}{2 \Delta x^{2}}\left(e^{I(k \Delta x)}-e^{-I(k \Delta x)}\right) & 1+\frac{\Delta t^{2}}{2 \Delta x^{2}}\left(e^{I(k \Delta x)}+e^{-I(k \Delta x)}\right)-\frac{\Delta t^{2}}{\Delta x^{2}}
\end{array}\right),
$$

atau dengan menggunakan identitas trigonometri maka dapat disederhanakan sebagai berikut:

$$
\left(\begin{array}{cc}
1+\frac{\Delta t^{2}}{\Delta x^{2}} \cos (k \Delta x)-\frac{\Delta t^{2}}{\Delta x^{2}} & -I \frac{\Delta t}{\Delta x} \sin (k \Delta x) \\
-I \frac{\Delta t}{\Delta x} \sin (k \Delta x) & 1+\frac{\Delta t^{2}}{\Delta x^{2}} \cos (k \Delta x)-\frac{\Delta t^{2}}{\Delta x^{2}}
\end{array}\right)
$$


Agar solusinya stabil haruslah modulo dari nilai eigen dari matriks amplifikasi itu kurang dari satu,

$$
1 \geq\left|\lambda_{1,2}\right|=\left|1+\frac{\Delta t^{2}}{\Delta x^{2}}(\cos (k \Delta x)-1) \pm I \frac{\Delta t}{\Delta x} \sin (k \Delta x)\right| .
$$

Persamaan yang terakhir ini merupakan suatu persamaan elips di bidang kompleks yang tergantung dari besar $\frac{\Delta t}{\Delta x}$. Agar modulo dari nilai eigen kompleks tersebut kurang dari 1, maka syarat kestabilan untuk skema Richtmyer tersebut yakni

$$
\mathrm{CFL}=\left|\frac{\Delta t}{\Delta x}\right| \leq 1
$$

Pemilihan ukuran grid $(\Delta x)$ dan timestep $(\Delta t)$ harus memenuhi persamaan (5.9), karena jika hubungan antara ukuran grid dan timestep lebih besar dari 1 akan menghasilkan solusi numerik berupa bilangan yang tak berhingga besarnya, sehingga pada waktu running program tidak didapatkan hasil karena eksekusi tidak bisa berhenti (terjadi blow-up). Pada makalah ini, nilai CFL yang kami gunakan adalah 0.9. Sebelumnya kami juga melakukan simulasi dengan beberapa CFL seperti yang dilakukan oleh Zhou dan Adewumi [9,10], yang harga CFL-nya berkisar antara 0.03 dan 0.35 . Demikian juga telah kami lakukan simulasi dengan skema Godunov dengan CFL antara 0.3 sampai dengan 0.7 [8]. Dari trial and error dapat disimpulkan bahwa nilai CFL yang lebih besar berakibat pada waktu komputasi (running program) yang lebih singkat, tetapi tidak mengakibatkan perubahan hasil simulasi yang cukup signifikan terhadap data lapangan.

\section{Syarat Batas}

Pada dasarnya, kondisi batas untuk line packing dirumuskan sesuai dengan kondisi di lapangan. Fakta yang terjadi di lapangan mengatakan bahwa laju alir inlet dan outlet dapat dikontrol sehingga syarat batas dari fluks massa, $m$ sudah diketahui, berbeda halnya dengan rapat massa dimana dibutuhkan trik khusus untuk mengatasi fakta bahwa di lapangan tidak diketahui syarat batasnya.

Tinjau persamaan aliran (4.3) komponen yang pertama, yaitu:

$$
\frac{\partial \rho}{\partial t}+\frac{\partial m}{\partial x}=0
$$


Secara sederhana persamaan di atas dapat diartikan bahwa jika dalam suatu segmen pipa sepanjang $\Delta x$ tidak ada perubahan fluks massa $(m), \frac{\partial m}{\partial x}=0$, maka rapat massanya tidak akan berubah terhadap waktu. Sifat ini akan dimanfaatkan dengan cara menambahkan satu segmen lagi sebelum inlet dan sesudah outlet. Tiap segmen tersebut diisi dengan informasi fluks massa yang sama dengan di inlet dan di outlet. Hal ini bertujuan untuk memanfaatkan sifat di atas sehingga informasi rapat massa untuk segmen tersebut diisi dengan informasi saat sebelumnya.

Akhirnya kita dapat menerapkan skema Richtmyer tersebut secara penuh untuk rapat massa dari segmen inlet sampai dengan segmen di outlet dan untuk fluks massa hanya di interiornya saja karena syarat batas untuk fluks massa dapat dimodelkan dari kasus di lapangan.

\section{$7 \quad$ Syarat Awal}

Untuk melakukan proses numerik, tentunya dibutuhkan syarat awal dari masalah di atas. Dari asumsi yang digunakan, dikatakan bahwa aliran pipa pada kondisi awal adalah steady-state. Artinya saat itu tidak ada perubahan terhadap waktu dari semua sifat gas, dengan kata lain

$$
\left.\frac{\partial \rho}{\partial t}\right|_{t=0}=0 \text { dan }\left.\frac{\partial m}{\partial t}\right|_{t=0}=0 .
$$

Substitusikan ini pada persamaan (4.3) menjadi

$$
\begin{aligned}
& \frac{\partial m}{\partial x}=0, \\
& \frac{\partial}{\partial x}\left(\frac{m^{2}}{\rho}+\rho\right)=-\frac{f_{g} m|m|}{2 \rho} .
\end{aligned}
$$

Masalah di atas merupakan persamaan differensial biasa, dan akan menjadi masalah nilai awal bila diketahui $\rho(0)=1$ sehingga dengan mudah dapat dicari solusinya. Dari $\frac{\partial m}{\partial x}=0$, diketahui bahwa $m$ tidak berubah terhadap jarak, akibatnya solusi dari masalah persamaan differensial biasa di atas berbentuk, $\rho=\rho(l)$ dengan $l \in\left[0, \frac{L}{D}\right]$. Bila kedua ruas pada persamaan (7.1) bagian bawah diintegralkan akan didapatkan persamaan seperti di bawah ini.

$$
\frac{\ln \left(\rho^{2}\right)}{f_{g}}-\frac{\left(\rho^{2}-1\right)}{f_{g} m_{0}^{2}}=l .
$$


Karena $\rho=\rho(l)$, artinya bila diketahui besaran-besaran seperti mass flux, diameter, faktor gesekan, dapat dicari rapat massa setiap titik $l$ saat kondisi awal. Salah satu cara yang dapat digunakan untuk mencari rapat massa, $\rho$, di suatu titik dalam pipa misalkan $l_{0}$, yaitu dengan memindahkan $l_{0}$ pada ruas kanan ke ruas kiri, menjadi

$$
\frac{\ln \left(\rho^{2}\right)}{f_{g}}-\frac{\left(\rho^{2}-1\right)}{f_{g} m_{0}^{2}}-l_{0}=0 .
$$

Masalah di atas dapat dipandang sebagai masalah mencari akar suatu fungsi terhadap $\rho$, dimana dapat diterapkan metode Newton Raphson.

$$
f(\rho)=\frac{\ln \left(\rho^{2}\right)}{f_{g}}-\frac{\left(\rho^{2}-1\right)}{f_{g} m_{0}^{2}}-l_{0}=0 .
$$

Karena pipa dibagi menjadi beberapa segmen, misalkan $J$ segmen, dimana masing-masing segmen panjangnya $\Delta x$, maka besarnya rapat massa untuk masing-masing titik (kecuali di inlet, dimana diasumsikan sudah diketahui) dapat dihitung dengan mensubstitusikan $l_{0}=j \Delta x, j=1, \ldots, J$. Jadi telah didapatkan syarat awal untuk persamaan differensial parsial (4.3).

\section{$8 \quad$ Simulasi}

Untuk mengaplikasikan metode numerik Richtmyer pada keadaan sebenarnya yang terjadi di lapangan akan disimulasikan dua contoh kasus berikut ini.

\subsection{Kasus 1}

Kasus yang pertama diambil dari paper Adewumi [10] dengan tujuan untuk validasi skema numerik Richtmyer dengan data di lapangan. Pipa dengan panjang 300 kaki dan mempunyai diameter dalam pipa sebesar 24 inci diisi dengan gas dengan tekanan 600 psia. Pada kondisi awal $(t=0)$ diasumsikan tidak ada aliran yang terjadi sehingga tekanan gas dalam pipa uniform sama sebesar 600 psia, lalu saat $t>0$ laju alir di inlet dinaikkan secara linier hingga mencapai 600 MMSCF/D dalam waktu 0.145 detik. Setelah mencapai 600 MMSCF/D laju alir inlet kembali diturunkan ke nol saat 0.29 detik kemudian dipertahankan konstan. Sementara itu pipa ditutup di bagian outlet sehingga laju alirnya tetap nol, faktor gesekan yang dipakai sebesar 0.03. Simulasi dijalankan selama 0.8 detik dan menggunakan CFL sebesar 0.9. Pemilihan CFL ini dimaksudkan untuk mempercepat waktu komputasi, pemilihan CFL lainnya diperbolehkan selama memenuhi persamaan (5.9). Ilustrasi untuk skenario ini dapat dilihat pada Gambar 1. 


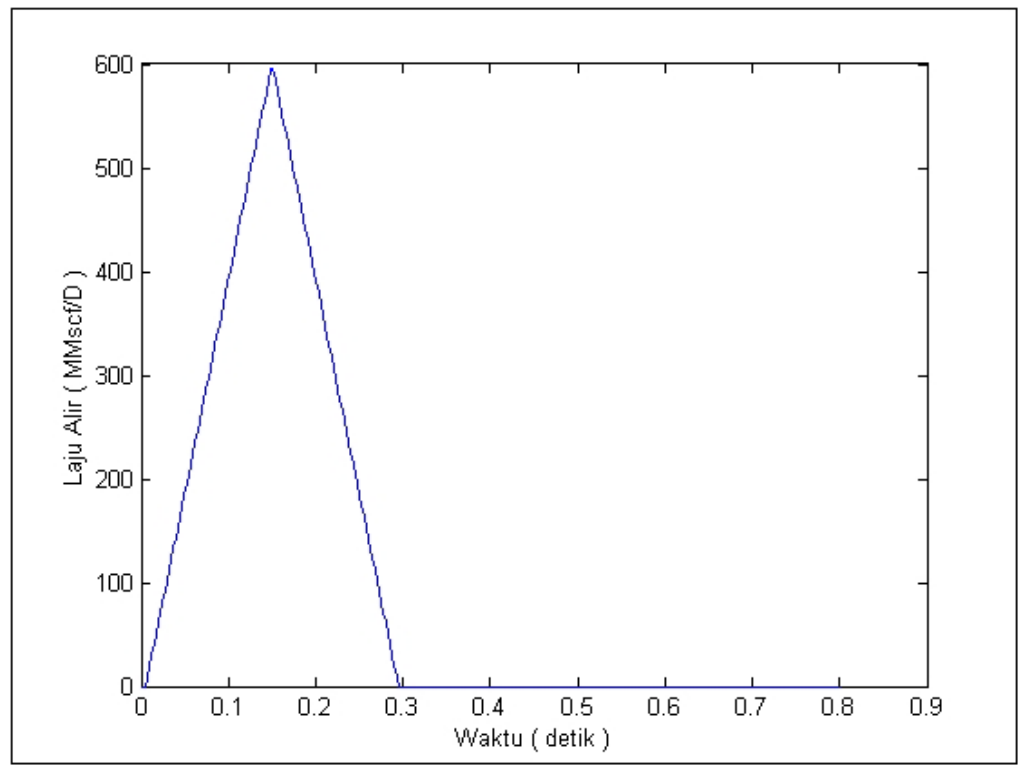

Gambar 1 Distribusi Laju Alir Inlet Terhadap Waktu.

Gambar 2 menunjukkan perbandingan antara prediksi tekanan gas di inlet terhadap waktu yang diperoleh dengan skema Richtmyer dengan data lapangan yang diambil dari [9].

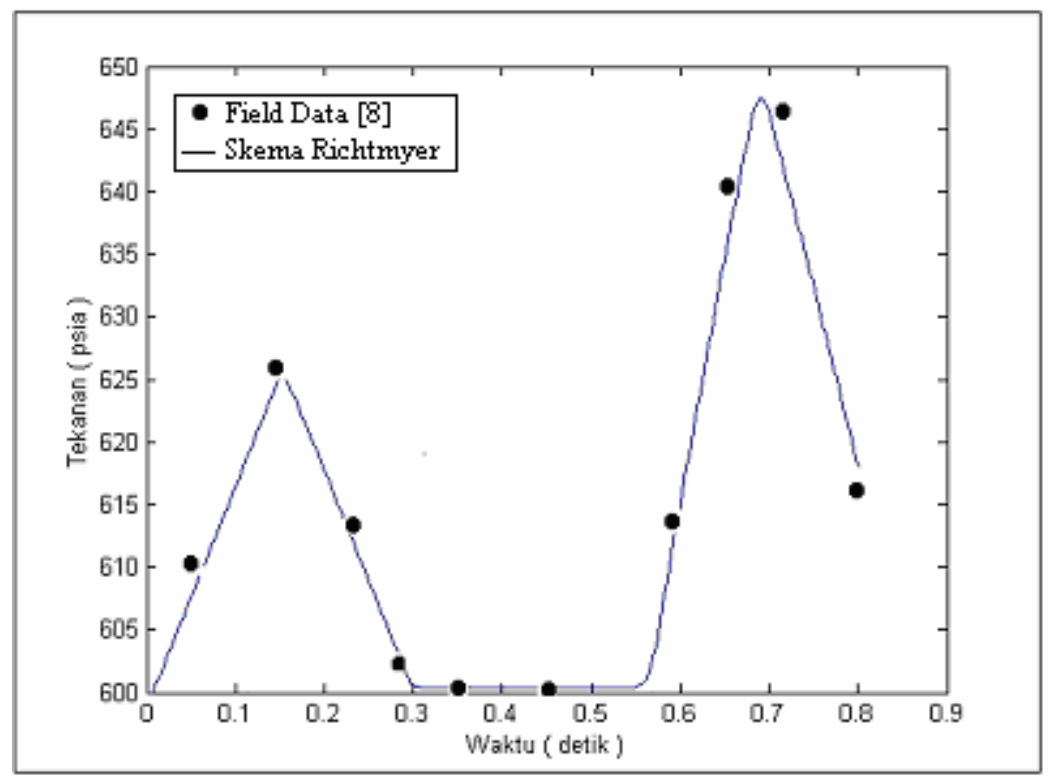

Gambar 2 Distribusi Tekanan Inlet Terhadap Waktu. 


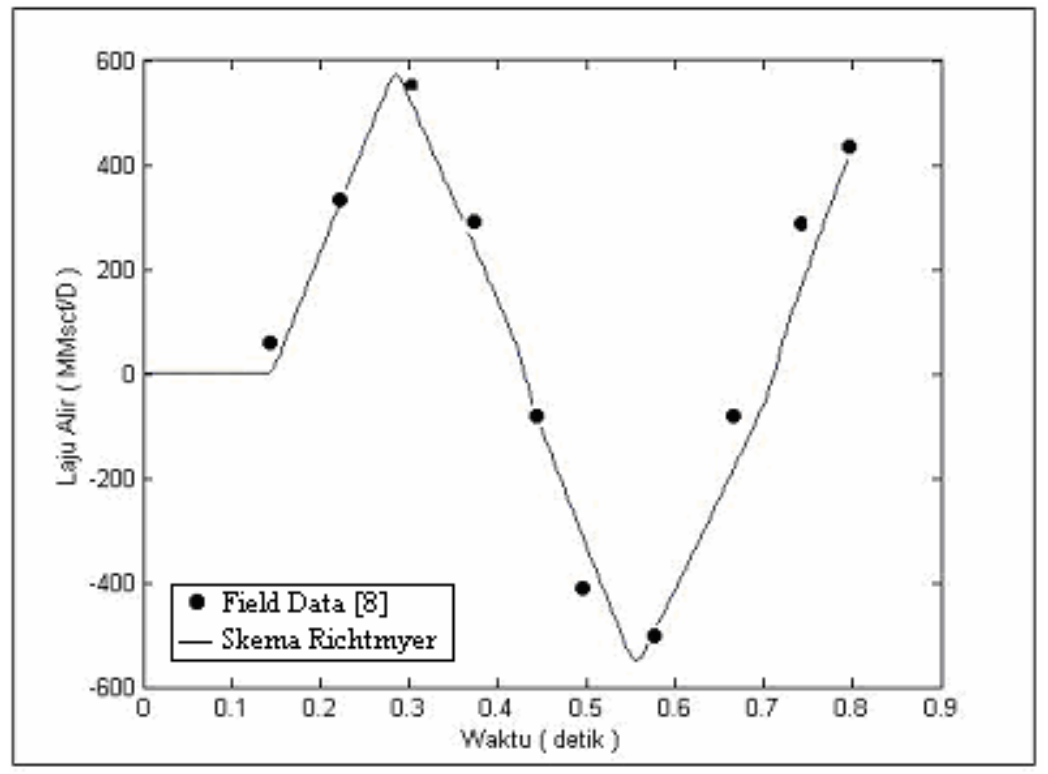

Gambar 3 Distribusi Laju Alir Midpoint Terhadap Waktu.

Sementara gambar 3 menunjukkan perbandingan antara laju alir di tengahtengah pipa (midpoint) terhadap waktu. Terlihat bahwa skema tersebut dapat memberikan prediksi yang cukup baik.

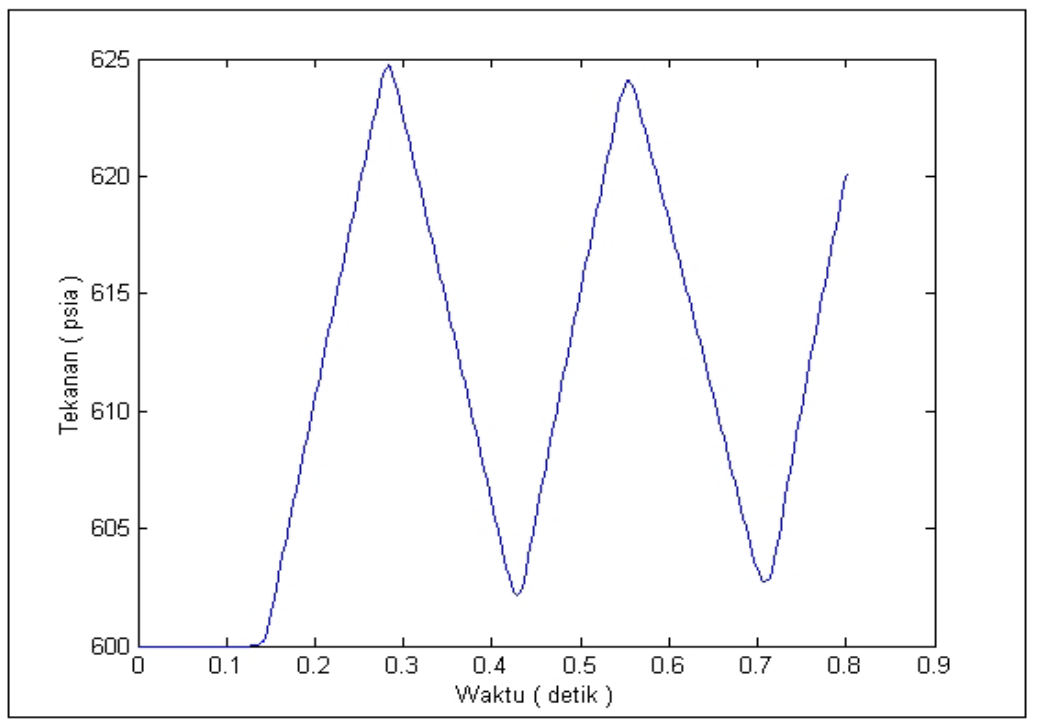

Gambar 4 Distribusi Tekanan Midpoint Terhadap Waktu (Skema Richtmyer). 


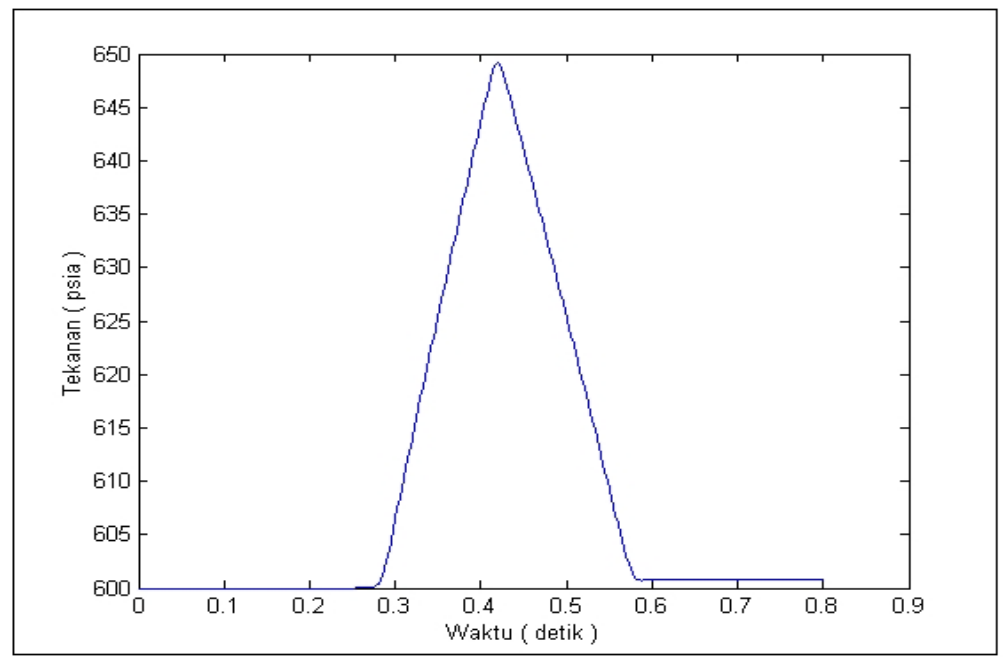

Gambar 5 Distribusi Tekanan Outlet Terhadap Waktu (Skema Richtmyer).

Gambar 4 dan 5 berturut-turut menunjukkan prediksi tekanan di midpoint dan di outlet. Gambar tersebut menunjukkan prediksi tekanan yang terjadi sepanjang pipa selama kondisi line packing. Laju alir inlet yang diperbesar memberi pengaruh cukup berarti terhadap perubahan tekanan di dalam pipa. Hal ini disebabkan karena laju alir di outlet tetap yang mengakibatkan gas tersimpan di dalam pipa setiap waktunya.

\subsection{Kasus 2}

Skenario yang kedua bertujuan membandingkan dua buah pipa dengan panjang yang berbeda namun mengalami kondisi yang sama khususnya dalam kondisi Line Packing. Pipa pertama dengan panjang 300 kaki dan pipa kedua dengan panjang 600 kaki. Simulasi pada kasus ini dijalankan selama 3 detik dan menggunakan skenario yang sama seperti pada kasus 1 . Pada awalnya di dalam pipa tidak ada aliran, dengan tekanan gas uniform sepanjang pipa sebesar 600 psia, lalu laju alir inlet dinaikkan secara linier mencapai $600 \mathrm{MMSCF} / \mathrm{D}$ dalam waktu 0.145 detik lalu diturunkan kembali ke nol saat waktu mencapai 0.29 detik. Faktor gesekan yang digunakan sebesar 0.03 dan simulasi ini dijalankan selama 3 detik.

Secara ringkas skenario untuk kasus ini masih sama seperti pada Gambar 1. Pertama-tama akan dibandingkan tekanan di inlet antara pipa dengan panjang 300 kaki dengan pipa dengan panjang 600 kaki.

Gambar 6 merupakan lanjutan dari kasus pertama dimana pada kasus pertama simulasi dijalankan hanya selama 0.8 detik. 


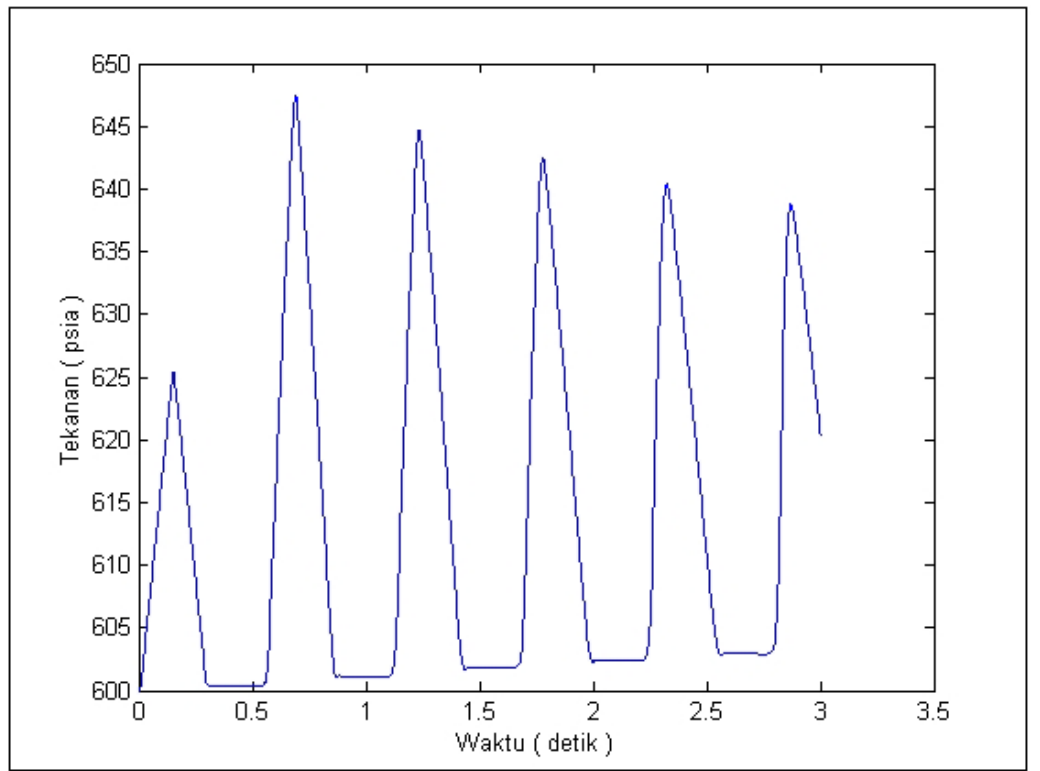

Gambar 6 Distribusi Tekanan Inlet Terhadap Waktu untuk pipa 300 Kaki (Skema Richtmyer).

Pada kasus ini bisa dibandingkan antara pipa dengan panjang 300 kaki (Gambar 6) dengan pipa dengan panjang 600 kaki (Gambar 7).

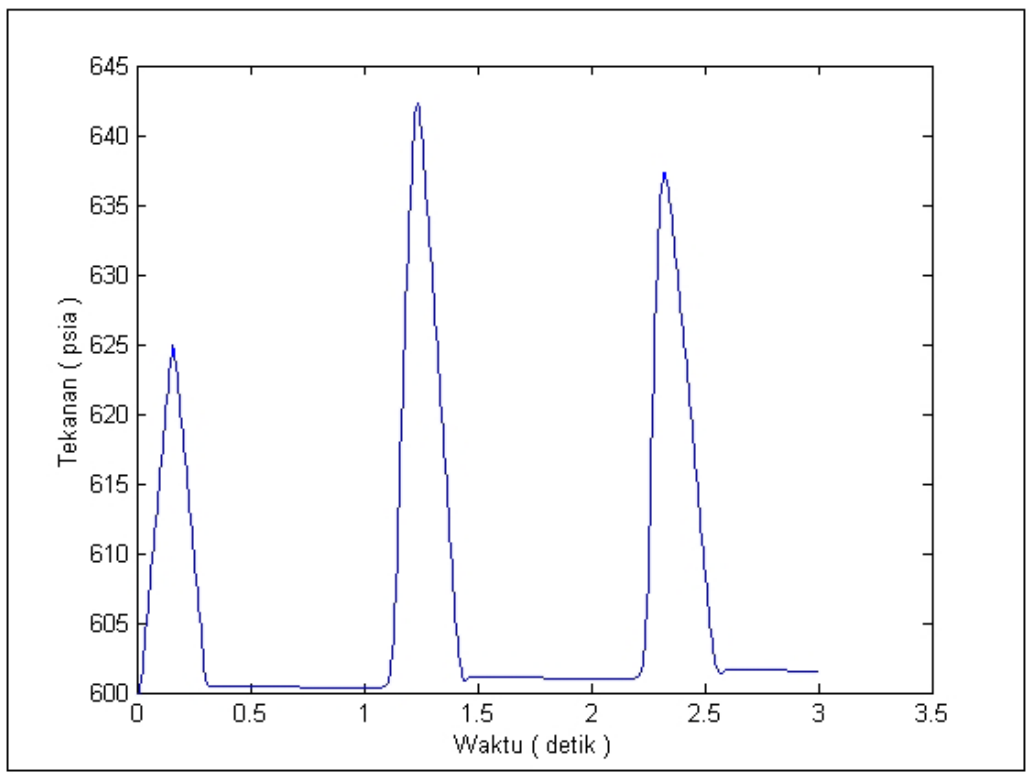

Gambar 7 Distribusi Tekanan Inlet Terhadap Waktu untuk pipa 600 Kaki (Skema Richtmyer). 


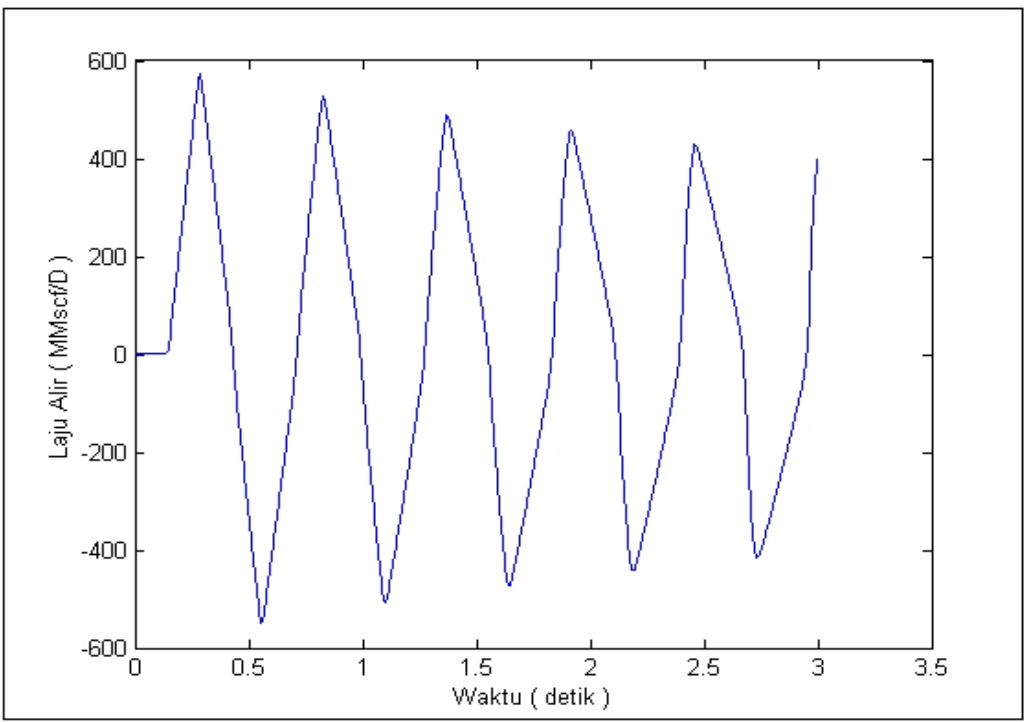

Gambar 8 Distribusi Laju Alir Midpoint Terhadap Waktu untuk pipa 300 kaki (Skema Richtmyer).

Terlihat bahwa gas yang tersimpan dalam pipa bergerak bolak-balik dari inlet ke oulet sebanyak 5 kali untuk pipa 300 kaki, sedangkan untuk pipa 600 kaki sebanyak 2 kali lebih. Lebih jelasnya dapat dilihat pada Gambar 8 dan 9.

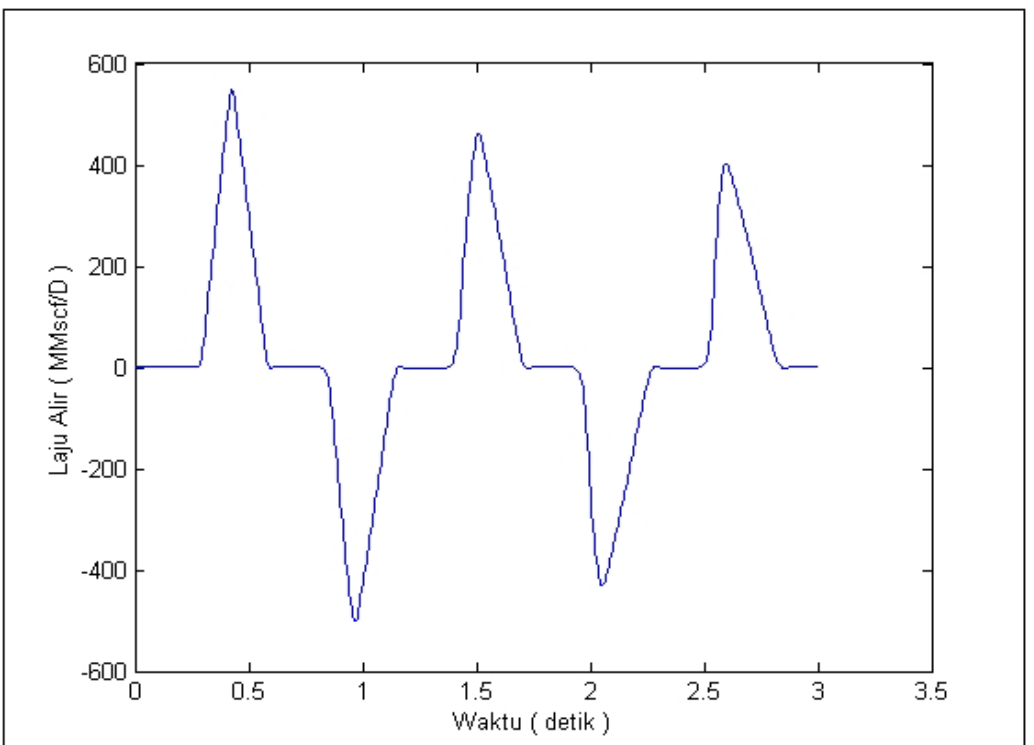

Gambar 9 Distribusi Laju ALir Midpoint Terhadap Waktu untuk pipa 600 kaki (Skema Richtmyer). 


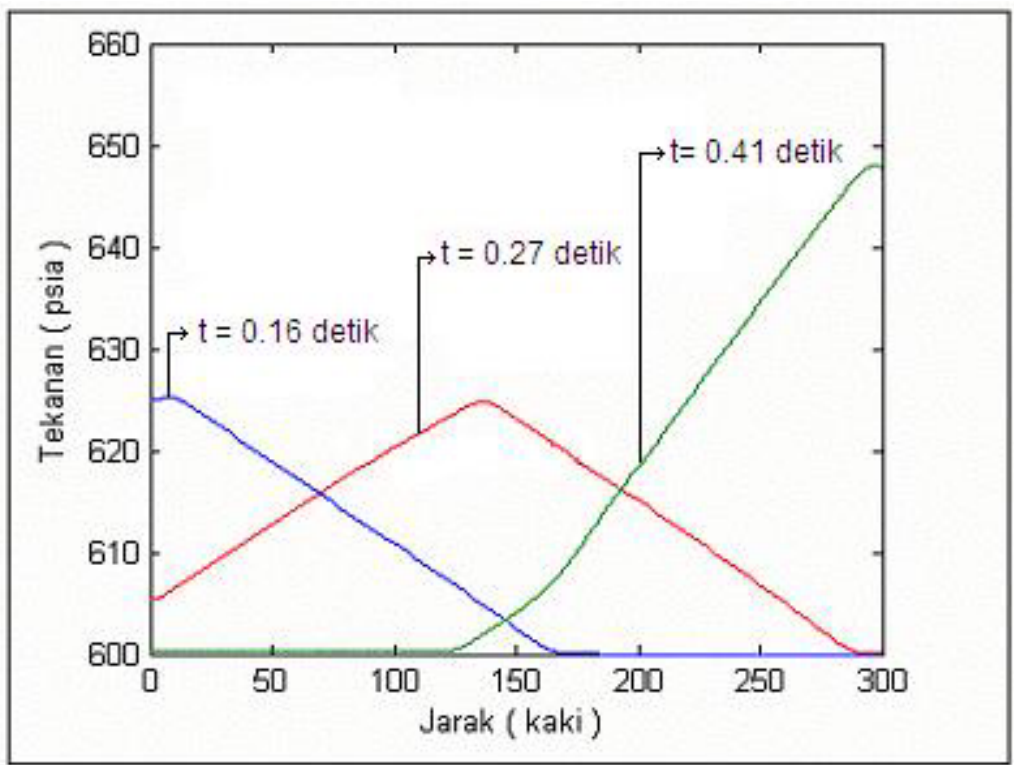

Gambar 10 Distribusi Tekanan sepanjang pipa untuk pipa 300 kaki (Skema Richtmyer).

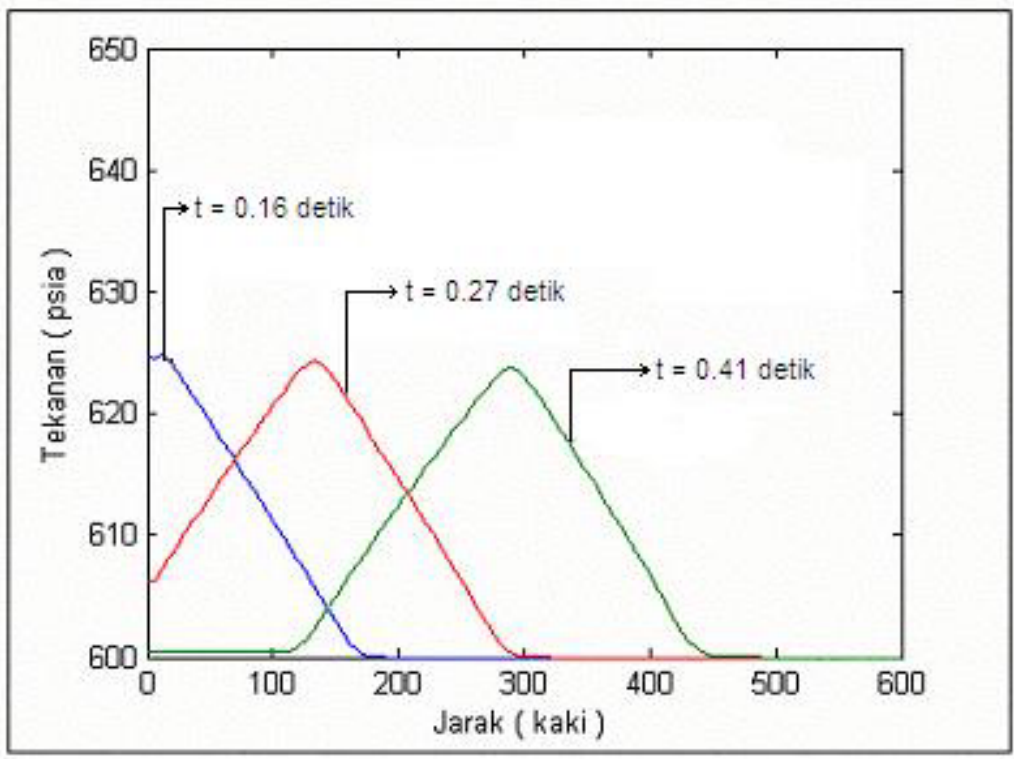

Gambar 11 Distribusi Tekanan sepanjang pipa untuk pipa 600 kaki (Skema Richtmyer). 
Gambar 10 dan 11 menyatakan distribusi tekanan pada beberapa waktu di dalam pipa. Waktu yang diambil untuk kedua pipa tersebut adalah sama yaitu pada $t=0.16, t=0.27$, dan $t=0.41$ detik. Bisa dilihat bahwa gas tersebut berjalan ke arah kanan gambar karena pipa tersebut diinjeksi gas. Yang menarik pada kedua gambar di atas adalah ketika $t=0.41$, dimana pada pipa 300 kaki (Gambar 10) gas telah sampai di outlet mengakibatkan tekanan gas meningkat hingga mencapai kira-kira 650 psia. Hal ini disebabkan oleh pipa di outlet yang ditutup. Bisa dilihat perbedaannya dengan pipa 600 kaki (Gambar 11) dimana gas masih terus berjalan ke arah kanan. Hal yang terjadi selanjutnya pada pipa 300 kaki setelah $t=0.41$, adalah gas tersebut akan berjalan ke arah kiri karena sekarang tekanan di inlet lebih kecil daripada di outlet, namun untuk pipa 600 kaki akan terus berjalan ke arah kanan sampai menyentuh outlet.

Skema Richtmyer merupakan skema yang lebih baik dari skema yang lain karena skema tersebut lebih sederhana daripada skema Lax Wendroff, dan lebih akurat dibanding dengan skema lain, seperti Backward Euler, Lax Friedrich dan Leapfrog [1,3]. Di pihak lain, skema Richtmyer mempunyai kekurangan yaitu tidak mampu mendeteksi gelombang shock dan gelombang rarefaction pada aliran gas. Skema lain yang mampu mengatasi masalah tersebut anatara lain adalah skema Godunov. Pada makalah ini, aliran gas yang disimulasikan mempunyai kecepatan yang jauh lebih lambat daripada kecepatan suara dalam gas. Dengan keadaan awal yang cukup halus, panjang pipa yang cukup pendek dan waktu simulasi yang cukup singkat, pembentukan gelombang shock dan rarefaction bisa diabaikan. Bentuk-bentuk simulasi seperti pada Gambar 8 dan 9 tidak memperlihatkan gelombang shock atau rarefaction melainkan hasil superposisi gelombang akibat penerapan syarat batas di sebelah kiri dan kanan pipa.

\section{$9 \quad$ Kesimpulan}

a. Suatu prosedur perhitungan untuk mensimulasikan aliran gas sepanjang pipa setiap waktunya dalam bentuk sistem persamaan diferensial parsial non-linier dan hiperbolik telah berhasil dikembangkan.

b. Skema Richtmyer dapat digunakan untuk menyelesaikan permasalahan aliran gas dalam pipa. Kestabilan yang dimiliki cukup baik, terlihat dari nilai CFL-nya yang bernilai

$$
\left|\frac{\Delta t}{\Delta x}\right| \leq 1 .
$$

c. Nilai CFL yang lebih besar (mendekati nilai 1) berakibat pada waktu komputasi (running program) yang lebih singkat, tetapi hal ini tidak 
mengakibatkan perubahan hasil simulasi yang cukup signifikan terhadap data lapangan.

\section{Daftar Simbol}

$$
\begin{array}{ll}
c & =\text { kecepatan suara dalam gas, } L / T \\
u & =\text { kecepatan gas, } L / T \\
\text { CFL } & =\text { konstanta Courant Friedrich Levy } \\
D & =\text { diameter dalam pipa, } L \\
f_{g} & =\text { faktor gesekan gas } \\
I & =\text { bilangan imajiner } \\
L & =\text { panjang total pipa, } L \\
m & =\text { laju alir massa, } M / L^{2} T \\
m_{0} & =\text { laju alir massa di inlet, } M / L^{2} T \\
p & =\text { tekanan, } M / L T^{2} \\
T & =\text { temperatur absolut gas } \\
t & =\text { waktu, } T \\
x & =\text { jarak, } L \\
\rho & =\text { densitas gas, } M / L^{3} \\
\rho_{0} & =\text { densitas gas di inlet, } M / L^{3} \\
\varepsilon & =\text { kekasaran pipa, } L \\
\Delta x & =\text { uniform grid size, } L \\
\Delta t & =\text { uniform time step, } T \\
&
\end{array}
$$

\section{Subskrip}

$$
\begin{array}{ll}
g & =\text { gas } \\
0 & =\text { kondisi di inlet }, \\
i-1, i, i+1 & =\text { titik-titik ke }(i-1), i, \text { dan }(i+1) \text { pada pipa }
\end{array}
$$

\section{Superskrip}

$$
n, n+1=\text { tingkatan waktu ke } n, n+1
$$

\section{Daftar Pustaka}

1. Hoffman, Joe. D., Numerical Methods For Engineers and Scientists, McGraw-Hill, Inc., Singapore, (1993).

2. Ikoku, Chi. U., Natural Gas Production Engineering, John Willey \& Sons Inc., Toronto, (1984).

3. LeVeque, Randall. J, Numerical Methods For Conservation Laws, Second Edition, Birkhäuser Verlag, Basel, (1992).

4. McCain, William D., Jr., The Properties of Petroleum Fluids, Second Edition, PennWell Publishing Company, Tulsa, (1990). 
5. Sod, G. A., A Survey of Several Finite Difference Methods for System of Nonlinear Hyperbolic Conservation Laws, Academic Press, Inc., New York, (1978).

6. Sukarno, P. \& Mucharam L., Aliran Multifasa dalam Pipa, Departemen Teknik Perminyakan ITB, Bandung, (2000).

7. Sulistyarso, H. Budiharjo., Mucharam, L., Siregar, S., Soewono, E., Darmadi, Saputra, I. \& Canggih, S., Analisa Perilaku Tekanan dan Laju Alir Gas Pada Pipa Transmisi Untuk Kasus Line Packing, Indonesian Pipeline Technology 2004 Conference Proceeding, S. Soepriyanto, A Taufik, ed., pp. 20:1-16, Department of Mining Engineering ITB, Bandung, (2004).

8. Sulistyarso, H. Budiharjo., Mucharam, L., Siregar, S., Soewono, E., Darmadi, Saputra, I. \& Canggih, S., Model Aliran Gas pada Pipa Transmisi dengan Kondisi Line Packing untuk Berbagai Diameter, Prosiding Seminar Sehari Ikatan Ahli Teknik Perminyakan Indonesia, Aris Buntoro, Bambang Bintarto, ed., hal 112-121, Ikatan Ahli Teknik Perminyakan Indonesia Komda Jateng \& DIY, Yogyakarta, (27 Agustus 2004).

9. Zhou, J. \& Adewumi, M. A., Simulation of Transient Flow in Natural Gas Pipeline, Paper PSIG \#9508, Published in www.psig.org, (1995).

10. Zhou, J. \& Adewumi, M. A., Simulation of Transients in Natural Gas Pipeline, Paper SPE\#31024, Presented at Offshore Technology Conference, Held in Houston, (May 1-4 1995).

11. Zhou, Junyang \& Adewumi, M. A., The Development and Testing of a New Flow Equation, Proceedings of PSIG Meeting, Houston, TX, (1995). 